\title{
AVALIAÇÃO DE BACTÉRIAS EXTREMÓFILAS FACULTATIVAS NA PRODUÇÃO DE FITOMASSA DO HÍBRIDO "UROGRANDIS" DE EUCALIPTO, A PARTIR DE SEMENTES ${ }^{1}$
}

\author{
Eder Marques² e Carlos Hidemi Uesugi ${ }^{2}$
}

\begin{abstract}
RESUMO - Atualmente, a árvore mais plantada no Brasil é o Eucalyptus spp., ocupando 81,6\% das florestas plantadas. Sua produtividade em 2009 foi de $44,2 \mathrm{~m}^{3}$ de eucalipto com casca/ha, gerando aproximadamente 46.850 empregos diretos. Estudos de bactérias benéficas, como as Rizobactérias Promotoras de Crescimento de Plantas (RPCPs), vêm sendo desenvolvidos há mais de um século. Este trabalho objetivou avaliar estirpes de bactérias extremófilas facultativas que possuam potencial na promoção de crescimento do eucalipto. As sementes do híbrido "urograndis" foram microbiolizadas com uma suspensão de $10^{9} \mathrm{UFC} / \mathrm{mL}$ das 10 estirpes bacterianas, através da agitação a $150 \mathrm{rpm}$, em incubador rotativo a $28^{\circ} \mathrm{C}$, por $24 \mathrm{~h}$. Em seguida, foram plantadas em sementeiras e mantidas em casa de vegetação. Após 60 dias, avaliou-se o peso de matéria seca da parte aérea e das raízes. O peso de matéria seca da parte aérea revelou que todas as estirpes bacterianas resultaram em ganhos quando comparado com o da testemunha, variando entre 11,3 e 78,0\%. Entretanto, as estirpes UnB 1366, UnB 1371, UnB 1375, UnB 1370 e UnB 1373 foram as que se diferiram significativamente. Em contrapartida, a estirpe UnB 1368 (Bacillus sp.) destacou-se individualmente no incremento (130,0\%) da biomassa radicular. Tais estirpes devem ser mais bem estudadas, quanto a formas de veiculação, combinações, formulações etc., para que possam ser utilizadas na otimização da produção de mudas.
\end{abstract}

Palavras-chave: Microbiolização de sementes, Produção de muda, Biomassa de raiz.

\section{EVALUATION OF FACULTATIVE EXTREMOPHILE BACTERIA IN THE PHYTOMASS PRODUCTION OF THE HYBRID "UROGRANDIS" OF EUCALYPTUS FROM SEEDS}

\begin{abstract}
Currently, Eucalyptus spp. is the tree that is most widely planted in Brazil, occupying $81.6 \%$ of planted forests. In 2009 its productivity was $44.2 \mathrm{~m}^{3}$ of eucalyptus with bark/hectare, generating about 46,850 direct jobs. Studies of beneficial bacteria, such as plant growth-promoting rhizobacteria (PGPRs), have been carried out for more than a century. The objective of this work was to evaluated strains of facultative extremophile bacteria that show potential in promoting eucalyptus growth. Seeds from the hybrid "urograndis" were microbiolized with a suspension of $10^{9} \mathrm{UFC} / \mathrm{mL}$ from 10 bacterial strains, by means of shaking at $150 \mathrm{rpm}$ in a rotating incubator, at $28^{\circ} \mathrm{C}$ for $24 \mathrm{~h}$. Next, they were planted in seed-trays and kept in the greenhouse. After 60 days seed germination and dry weight of the aerial part and roots were evaluated.. The dry weight of the aerial part revealed that all the bacterial strains produced gains when compared to the control, varying from 11.3 to $78.0 \%$. However, strains UnB 1366, UnB 1371, UnB 1375, UnB 1370 and UnB 1373 were the ones that differed significantly. In contrast, the UnB 1368 strain (Bacillus sp.) stood out individually in promoting an increase of $130.0 \%$ in root biomass. These strains should be more thoroughly studied with regard to vehicle, combinations, formulations and others, so that they may be used in optimizing seedling production.
\end{abstract}

Keywords: Root biomass, Seed microbiolization, Seedling production.

\footnotetext{
${ }^{1}$ Recebido em 17.02.2012 aceito para publicação em 20.12.2012.

${ }^{2}$ Departamento de Fitopatologia da Universidade de Brasília, DF, Brasil. E-mail: <uesugich@ unb.br>e <edermarques@ pop.com.br>.
} 


\section{INTRODUÇÃOO}

As florestas naturais no mundo somam cerca de 4 bilhões de hectares, cobrindo aproximadamente $30 \%$ da superfície terrestre do globo (SBS, 2008). Cinco países concentram mais da metade da área florestal total: Rússia, Brasil, Canadá, Estados Unidos e China. No Brasil, que é o segundo maior, a área florestal total absoluta é de aproximadamente 851,4 milhões de hectares. Desse total, apenas $0,7 \%$ é de florestas plantadas, e destas $81,6 \%$ são com eucalipto (ABCP, 2009). O crescimento da área de florestas plantadas no país foi de $27,11 \%$ entre os anos 2004 e 2009 (ABPFP, 2011).

Microrganismos que habitam o solo desempenham diversas funções, como: decomposição de matéria orgânica e agregação do solo, além do controle biológico de pragas e doenças (SIQUEIRA, 1993; MOREIRA; SIQUEIRA, 2006). Entre esses organismos, as bactérias constituem o grupo mais numeroso, podendo variar de acordo com o tipo de solo, manejo e métodos de isolamento empregados (BRANDÃO, 1992). Estima-se que menos de $10 \%$ da vida no solo seja conhecida, isso para não falar da falta de conhecimento do potencial desses organismos (MENDES; REIS JR., 2010).

Sabe-se que em determinados materiais genéticos de Eucalyptus spp., em fase de multiplicação, o índice de enraizamento é baixo, dificultando o processo de clonagem (MAFIA et al., 2009). Além disso, na propagação vegetativa por miniestaquia do eucalipto, amplamente empregada, ainda se observa heterogeneidade no enraizamento (TEIXEIRA, 2001). Dessa forma, muitos desses organismos do solo e da rizosfera, que têm grande potencial na promoção do crescimento e enraizamento de plantas, podem ser utilizados na minimização de tal limitação.

As chamadas Rizobactérias Promotoras de Crescimento de Plantas (RPCPs), termo inicialmente utilizado para descrever bactérias benéficas bem adaptadas às raízes das plantas (KLOEPPER; SCHORTH, 1978) e para diferenciá-las das bactérias do solo que não colonizam ou não o fazem tão agressivamente, estão entre os organismos utilizados no aumento da produção de plantas (ZAGO et al., 2000). Elas têm sido utilizadas na biofertilização, biorremediação, biopesticidas e fitoestimulantes (MAFIA et al., 2007). A maioria das estirpes de RPCPs documentadas, até então, pertence aos gêneros Pseudomonas (gram-negativas) e Bacillus (gram-positivas)
(LUZ, 1996). Dentro do gênero Pseudomonas, o maior número das espécies refere-se ao grupo das fluorescentes (LATOUR; LEMANCEAU, 1997).

A prospecção de tais organismos pode ser realizada diretamente do solo, assim como do interior das plantas (PAZ, 2009), ou mesmo, do rizoplano (LEMOS, 2009). Segundo Romeiro (2007), vários parâmetros podem ser analisados para avaliar a promoção do crescimento, como percentagem de germinação de sementes, tempo de germinação, altura da planta, número de folhas, peso de matéria seca da parte aérea e raízes, além do peso de matéria seca de toda a planta.

Grande parte das RPCPs apresenta um ou mais mecanismos de ação, que podem ser divididos em: de ação indireta, ou seja, de controle de patógenos e de ação direta, que promovem o crescimento direto das plantas. Entre eles, podem-se citar: fixação de nitrogênio (Bacillus sp.), produção de fitormônios (Bacilus subtilis, giberelinas), de ácido hidrociânico (Pseudomonas fluorescens), mineralização de nutrientes (Pseudomonas putida, disponibilização de fósforo), produção de sideróforos (Pseudomonas fluorescentes, pioverdina), indução de resistência (Pseudomonas sp.), produção de bacteriocinas (Agrobacterium radiobacter, Agrocina K-84), antibióticos (Bacilus subtilis, bacilizina), competição por substrato (Pseudomonas fluorescens, competição por $\mathrm{Fe}^{3+}$ ), parasitismo (Enterobacter cloacae, degradação de micélio de Pythium) etc. (LUZ, 1996).

Número reduzido de trabalhos descreve RPCPs em eucalipto. Por exemplo, Mafia et al. (2005) avaliaram o efeito de rizobactérias promotoras incorporadas ao substrato de minijardins clonais de eucalipto, sendo observado incremento da biomassa radicular, além de diferenças significativas na produção de miniestacas. Zarpelon (2007) avaliou a formulação de um inoculante (Rizolyptus ${ }^{\circledR}$ ), contendo várias espécies bacterianas, no enraizamento e crescimento do eucalipto. Alta eficiência no enraizamento de miniestacas e crescimento de mudas, variando de acordo com o clone, tipo de formulação e isolado testado, foi relatada. Avaliando isolados da rizosfera de eucalipto, Teixeira et al. (2007) descreveram isolados que propiciaram ganhos no enraizamento e no peso de matéria seca de raízes, também variando de acordo com o clone e isolado testados. Mafia et al. (2007) relataram incrementos significativos na velocidade, no índice de enraizamento e na biomassa radicular, com a aplicação de fonte alimentar inicial junto com isolados de rizobactérias. Não houve interação 
entre isolados e substratos de enraizamento. Rizobactérias obtidas a partir da rizosfera de mudas clonais de eucalipto de diferentes regiões do país foram avaliadas quanto ao índice de enraizamento, biomassa radicular e incidência de doenças. Em geral, todos os isolados aumentaram o enraizamento e a biomassa radicular e promoveram o controle biológico de Cylindrocladium spp. (MAFIA et al., 2009).

Embora estudos recentes relatem a utilização de bactérias benéficas no Brasil, número reduzido de trabalhos trata da presença natural dessas espécies bacterianas no solo, principalmente em se tratando de bactérias que crescem fora da faixa da neutralidade. Neste trabalho, utilizou-se o termo extremófilos facultativos para designar bactérias capazes de crescer tanto em condições mais extremas quanto em condições mais próximas da neutralidade (mesófilos). Como existem poucos relatos desses organismos em solos e seu potencial ainda é pouco conhecido (MADIGAN, 2000), foram objetivos deste trabalho: testar estirpes de bactérias extremófilas facultativas previamente isoladas e identificadas, que possuam potencial na promoção de crescimento do eucalipto.

\section{MATERIAL E MÉTODOS}

\subsection{Local de realização dos ensaios}

Os experimentos foram inicialmente conduzidos no Laboratório de Bacteriologia Vegetal, do Departamento de Fitopatologia do Instituto de Ciências Biológicas da Universidade de Brasília, onde as culturas e suspensões bacterianas foram preparadas e as sementes microbiolizadas, estabelecidas em casa de vegetação da Estação Experimental de Biologia dessa mesma instituição, onde as sementes foram plantadas em bandejas de isopor.

\subsection{Origem das estirpes bacterianas}

As estirpes bacterianas, recuperadas da Coleção de Bactérias do Departamento de Fitopatologia da Universidade de Brasília, foram obtidas originalmente de estudos anteriores (MARQUES, 2012), sob diferentes condições de $\mathrm{pH}$ e salinidade e identificadas com base no sequenciamento do gene do $16 \mathrm{~S}$ rDNA (Tabela 1).

\subsection{Testes de promoção de crescimento via microbiolização de sementes}

Os testes foram realizados via microbiolização de sementes com metodologia adaptada de Rodrigues (2010), utilizando-se sementes do híbrido Eucalyptus grandis x Eucalyptus urophylla ("urograndis") cedidas pelo Instituto de Pesquisas e Estudos Florestais (IPEF - SP). A desinfestação superficial das sementes de eucalipto foi efetuada por imersão em álcool 70\% (30 seg), seguida da imersão em solução de hipoclorito de sódio $1 \%$ (3 min) e lavagem em água destilada esterilizada, por duas vezes consecutivas. A partir de então, as sementes foram imersas em uma suspensão bacteriana (Tabela 1) na concentração de $10^{9} \mathrm{UFC} / \mathrm{mL}$ (Escala 7 de McFarland), agitadas a $150 \mathrm{rpm}$ em incubador rotativo, a $28{ }^{\circ} \mathrm{C}$, por $24 \mathrm{~h}$, com exceção das sementes-testemunha que foram mantidas nas mesmas condições, porém em água destilada estéril. Após esse período, aproximadamente $0,05 \mathrm{mg}$ das sementes microbiolizadas foram semeadas em 60 células de bandejas de isopor ( 72 células) contendo o substrato Bioplant ${ }^{\circledR}$ e mantidas em bancadas sobre estrados plásticos para evitar possível contaminação entre os tratamentos. Considerando que as sementes de "urograndis" são muito pequenas e não se consegue plantar apenas uma, foi realizado o raleio 15 D.A.E (dias após a emergência), mantendo-se uma planta por célula.

\subsection{Condução do estudo}

A 30 D.A.E. foi realizada a adubação com o fertilizante líquido Casa Verde $\left(\right.$ Dimy $\left.^{\circledR}\right)$ na formulação de NPK 08-08-08, sendo administrada conforme a recomendação do fabricante $(7,5 \mathrm{~mL} / \mathrm{L}$ de água), por meio de rega das plântulas. Após 60 dias da semeadura, avaliaram-se o crescimento e enraizamento pela análise do peso de matéria seca da parte aérea e das raízes. A parte aérea foi separada da raiz na altura do coleto, e em seguida as raízes foram lavadas para retirar o substrato. As respectivas partes foram acondicionadas em sacos de papel individualmente e levadas à estufa, por $24 \mathrm{~h}$ $48 \mathrm{~h}$ a $70^{\circ} \mathrm{C}$, após atingir massa constante, e pesadas em balança digital.

\subsection{Delineamento experimental e análises estatísticas}

O delineamento utilizado foi o inteiramente casualizado com 10 tratamentos (estirpes bacterianas) constituídos de 60 repetições (parcelas experimentais), com mais uma testemunha. Os dados do ensaio foram submetidos à análise de variância (ANOVA), utilizando o programa Assistat 7.6 beta (SILVA; AZEVEDO, 2009). Os valores médios de peso de matéria seca da parte aérea e das raízes foram comparados pelo teste $\mathrm{T}$, a $5 \%$ de probabilidade.

Revista Árvore, Viçosa-MG, v.37, n.1, p.41-47, 2013 
Tabela 1 - Efeito das estirpes bacterianas oriundas de condições extremas na produção de fitomassa do híbrido "urograndis" de eucalipto obtidos de sementes.

Table 1 - Effect of bacterial strains, originating from extreme conditions, on the phytomass production of the hybrid "urograndis" of eucalyptus obtained from seeds.

\begin{tabular}{|c|c|c|c|c|c|c|}
\hline \multicolumn{3}{|c|}{ Tratamentos } & \multicolumn{2}{|c|}{$\begin{array}{c}\text { Peso de matéria } \\
\text { seca da parte aérea }\end{array}$} & \multicolumn{2}{|c|}{$\begin{array}{c}\text { Peso de matéria } \\
\text { Seca de raiz }\end{array}$} \\
\hline Estirpes & $\begin{array}{c}\text { Condição de } \\
\text { isolamento } \\
\end{array}$ & Gênero & $\begin{array}{l}\mathrm{MG}^{1}: 0,16073 \\
\text { CV\% }{ }^{2}: 68,32 \\
\end{array}$ & $\begin{array}{c}\text { Incremento }^{4} \\
\% \\
\end{array}$ & $\begin{array}{l}\text { MG: } 0,06149 \\
\text { CV\%: } 76,25\end{array}$ & $\begin{array}{c}\text { Incremento } \\
\%\end{array}$ \\
\hline UnB 1366 & pH 3 & Bacillus sp. & $0,19046 a^{3}$ & $78,0 \mathrm{a}$ & $0,05464 \mathrm{bcde}$ & $16,2 \mathrm{bcde}$ \\
\hline UnB 1367 & $\mathrm{pH} 5$ & Enterobacter sp. & $0,11923 b c$ & $11,3 \mathrm{bc}$ & $0,04196 \mathrm{e}$ & NA \\
\hline UnB 1368 & $\mathrm{pH} 5$ & Bacillus sp. & $0,15848 \mathrm{ab}$ & $48,0 \mathrm{ab}$ & $0,10811 \mathrm{a}$ & $130,0 \mathrm{a}$ \\
\hline UnB 1369 & $\mathrm{pH} 7$ & Enterobacter sp. & $0,1625 \mathrm{ab}$ & $52,0 \mathrm{ab}$ & $0,07041 b$ & $50,0 \mathrm{~b}$ \\
\hline UnB 1370 & $\mathrm{pH} 7$ & Enterobacter sp. & $0,17330 \mathrm{a}$ & $62,0 \mathrm{a}$ & $0,05198 \mathrm{bde}$ & 10,6 bde \\
\hline UnB 1371 & $\mathrm{pH} 7$ & Enterobacter sp. & $0,18912 \mathrm{a}$ & $76,6 \mathrm{a}$ & $0,06397 \mathrm{bcd}$ & $36,1 \mathrm{bcd}$ \\
\hline UnB 1372 & pH 9 & Bacillus sp. & $0,13657 \mathrm{abc}$ & $27,5 \mathrm{abc}$ & $0,06244 \mathrm{bcde}$ & 33,0 bcde \\
\hline UnB 1373 & $\mathrm{pH} 10$ & Enterobacter sp. & $0,16745 \mathrm{a}$ & $56,4 \mathrm{a}$ & $0,06916 b c$ & $47,1 \mathrm{bc}$ \\
\hline UnB 1374 & $10 \% \mathrm{NaCl}$ & Bacillus sp. & $0,13836 a b c$ & $29,2 \mathrm{abc}$ & 0,04698 bde & NAbde \\
\hline UnB 1375 & $15 \% \mathrm{NaCl}$ & Bacillus sp. & $0,18248 \mathrm{a}$ & $70,4 \mathrm{a}$ & $0,05154 b^{b} e^{5}$ & 9,6 \\
\hline Testemunha & $\mathrm{NA}^{5}$ & NA & $0,10707 \mathrm{c}$ & NA & 0,04701 bde & NA \\
\hline
\end{tabular}

${ }^{2}$ Coeficiente de variação. ${ }^{3}$ Valores seguidos da mesma letra dentro da mesma coluna não diferem significativamente a 5\% de probabilidade pelo teste T. ${ }^{4}$ Incremento em relação à testemunha. ${ }^{5} \mathrm{NaO}$ se aplica neste caso.

\section{RESULTADOS}

A técnica de microbiolização de sementes revelou na análise geral das médias do peso de matéria seca da parte aérea que todas as estirpes levaram a ganhos, embora alguns tratamentos não tenham diferido estatisticamente (Tabela 1). A estirpe UnB 1366 foi a que mostrou maior média neste parâmetro, promovendo o incremento de 78,0\%, em comparação com a testemunha e diferindo-se estatisticamente dela. Entretanto, ela não exibiu diferença estatística significativa com as estirpes UnB 1371, UnB 1375, UnB 1370, UnB 1373, UnB 1369, UnB 1368, UnB 1374 e UnB 1372. A estirpe UnB 1367 não diferiu do tratamento com as estirpes UnB 1368, UnB 1369, UnB 1372 e UnB 1374. No entanto, a testemunha não diferiu estatisticamente dos tratamentos com as estirpes UnB 1367, UnB 1372 e UnB 1374, e estes conjuntamente tiveram os menores valores de incremento de massa seca da parte aérea.

Comparando agora as médias da massa seca das raízes, pôde-se observar que o isolado UnB 1368 foi o que se destacou, promovendo o maior incremento do peso de $130,0 \%$ e diferindo-se estatisticamente da testemunha e de todos os demais tratamentos. Diferentemente, a estirpe UnB 1369 não se diferiu dos outros tratamentos, exceto da estirpe UnB 1367, que mostrou a menor biomassa de raízes e não mostrou diferença estatística significativa com UnB 1366, UnB 1370, UnB 1372, UnB 1374, UnB 1375 e, por fim, com a testemunha. Os tratamentos com as estirpes UnB 1367 e UnB 1374 não proporcionaram incremento no peso de matéria seca de raízes.

\section{DISCUSSÃO}

No estudo em questão, foi utilizada a técnica de microbiolizar as sementes com bactérias e que levou a resultados positivos. Não existem estudos conclusivos da interação entre isolados e genótipos de plantas de interesse, ou da melhor forma de veiculação ou formulação. Como o tempo de produção no setor florestal é longo, o uso de bactérias benéficas não visa ao aumento direto da produção de madeira e, sim, aumentar o índice de sobrevivência e precocidade no estabelecimento em campo após o plantio (MAFIA et al., 2007). A principal forma de veiculação dessas bactérias é via microbiolização de sementes, principalmente quando o objetivo é o biocontrole de patógenos no solo (LUZ, 1993). Dessa forma, nem sempre é comparável resultados de estudos de promoção de crescimento utilizando diferentes tipos de ensaios, formulações, clones, sementes etc. Por sua vez, os resultados deste trabalho são inovadores por se tratar do uso do método de microbiolização de sementes na promoção de crescimento, podendo tais 
estirpes ser utilizadas, por exemplo, na otimização em campos de produção e melhoramento ou, mesmo, na microbiolização de estacas.

Entre as estirpes estudadas, isoladas em solos sob condições ambientais extremas, a maior parte delas foi capaz de promover o incremento tanto da biomassa da parte aérea quanto das raízes. Aqui tais estirpes foram chamadas de extremófilas facultativas, pois crescem fora da faixa das mesófilas e mostraram características benéficas na promoção de crescimento. Os estudos de identificação de bactérias de solo que desempenham diversas funções (SIQUEIRA, 1993; MOREIRA; SIQUEIRA, 2006), mas que crescem em condições fora da faixa das mesófilas, são incipientes. Presume-se que esses organismos por terem habilidade de sobreviver em tais condições possuam características desejáveis. Não se pode afirmar o mecanismo envolvido na promoção de crescimento. Seria algo a se investigar futuramente, mas sabe-se que tais bactérias podem atuar na fixação de nitrogênio, produção de fitormônios, de ácido hidrociânico, mineralização de nutrientes, produção de sideróforos (LUZ, 1996).

As estirpes pertencentes ao gênero Bacillus sp. foram as que proporcionaram os maiores ganhos de matéria seca da parte aérea e das raízes de 78,0\% (UnB 1366) e $130,0 \%$ (UnB 1368), respectivamente, em comparação com as estirpes do gênero Enterobacter sp. Inicialmente, o uso de fertilizantes bacterianos não simbiontes propiciavam ganhos de 10-20\% na produtividade em diversas culturas (BROWN, 1974). Segundo Chanway (1997), os ganhos médios seriam de 15 a $30 \%$ e, em casos especiais, até mesmo dobrar a biomassa produzida, mas obviamente esses valores são variáveis. Mafia et al. (2005), testando diferentes clones, observaram variação no incremento de biomassa radicular chegando a $69 \%$, com destaque para o isolado de B. subtilis. Zarpelon (2007) observou maior eficiência no enraizamento de miniestacas e crescimento de mudas em formulação turfosa de um isolado de B. subtilis (S1), com incremento de $47 \%$ de parte aérea e $40 \%$ de biomassa radicular. Isolados da rizosfera de eucalipto propiciaram ganhos de até $250 \%$ no peso de matéria seca de raízes (TEIXEIRA et al., 2007). Foram demonstrados ganhos no índice de enraizamento e de biomassa radicular em tratamento com a aplicação de fonte alimentar, enriquecida com leite em pó, variando entre 40,6 e 114,2\% de biomassa radicular, segundo Mafia et al. (2007). Mais tarde, Mafia et al. (2009) relataram a interação do isolado de rizobactéria 3918 (Bacillus subtilis) e o clone 1172 ("urograndis"), resultando em ganhos percentuais de 187,6\% também de biomassa radicular. Assim como neste estudo, Rezende (2010) avaliou isolados obtidos de condições extremas na promoção do crescimento do tomate. Porém, foram os gêneros pertencentes a Klebsiella sp. e Enterobacter sp. que mostraram os maiores incrementos de matéria seca total, respectivamente de $102,3 \%$ e $140,2 \%$.

Baixo incremento de massa seca de parte aérea e biomassa de raízes foi observado nos tratamentos com as estirpes UnB 1367 (Enterobacter sp.) e UnB 1374 (Bacillus sp.). Segundo Kloepper e Schorth (1978), as bactérias que colonizam o rizoplano podem ter efeito benéfico, neutro ou deletério às plantas hospedeiras, o que pode ter ocorrido nas estirpes citadas anteriormente. Procópio (2004), avaliando a promoção de crescimento em eucalipto com bactérias endofíticas dessa planta, também observou interação negativa.

Para otimizar a interação entre isolados e clones, torna-se necessário selecionar aqueles que são capazes de aumentar o enraizamento e crescimento de maior número de clones possível, além de estudos para aplicação da tecnologia em larga escala, em misturas e em formulação comercial (MAFIA et al., 2009). Existem poucos bioagentes comerciais à base de RPCPs. Eles englobam três gêneros: Agrobacterium, Bacillus e Pseudomonas. O emprego de tais bactérias é uma tática sustentável, diminuindo a utilização de produtos químicos, mas para isso uma série de problemas deve ser solucionada, fazendo com que seu uso eficaz seja implementado (LUZ, 1996).

\section{CONCLUSÃO}

O estudo de populações bacterianas benéficas, como as RPCPs, é um trabalho contínuo, tendo início há mais de um século. Neste trabalho, pioneiro no uso de baterias extremófilas facultativas, algumas estirpes mostraram resultados interessantes nos testes de promoção de crescimento, de forma que estudos pertinentes, como outras formas de veiculação das bactérias, formulações, adição de fontes alimentares, combinações, ou mesmo, utilização de outras espécies ou clones de eucalipto para verificação de interações, devem ser realizados para que possam ser utilizadas na otimização da produção de mudas, assim como a investigação do mecanismo de ação dessas bactérias.

Revista Árvore, Viçosa-MG, v.37, n.1, p.41-47, 2013 
Além disso, o uso de bactérias extremófilas facultativas pode ser vantajoso por suportar condições adversas do campo, em comparação com outras que não possuem essa característica.

\section{AGRADECIMENTOS}

Ao CNPq, pela concessão de bolsa de estudos ao primeiro autor, no curso de Doutorado; e ao Instituto de Pesquisas e Estudos Florestais, por ceder às sementes do híbrido "urograndis".

\section{REFERÊNCIAS}

\section{ASSOCIAÇÃO BRASILEIRA DE CELULOSE E} PAPEL - ABCP. Relatório florestal 2009 Disponível em: <http://bracelpa.org.br/bra2/sites/ default/files/public/RA02-RelatorioFlorestal_2009. pdf $>$. Acesso em: 06 ago. de 2011.

\section{ASSOCIAÇÃO BRASILEIRA DE PRODUTORES DE FLORESTAS PLANTADAS - ABPFP. Florestas plantadas no Ministério da Agricultura. Disponível em: <http:// www.abraflor.org.br/informativo/ABRAF224.pdf>. Acessado em: 06 jun. de 2011.}

BRANDÃO, E. M. Os componentes da comunidade microbiana do solo. In: CARDOSO, E. J. B.; TSAI, S. M.; NEVES, M. C. P. (Ed.) Microbiologia do solo. Campinas: Sociedade Brasileira de Ciência do solo, 1992. p. 1-15.

BROWN, M. E. Seed and root bacterization. Annual Review of Phytopathology, v.12, n.1, p.181-197, 1974.

CHANWAY, C. P. Inoculation of tree roots with PGPR soil bacteria: An emerging technology for reforestation. Forest Science, v.43, n.1, p.99$112,1997$.

KLOEPPER, J. W.; SCHROTH, M. M. Plant growth promoting rhizobacteria on radishes. In INTERNATIONAL CONFERENCE ON PLANT PATHOGENIC BACTERIA, 4., 1978, Angers. Proceedings... France: Angers: 1978. p.879-882.

LATOUR, X.; LEMANCEAU, P. Carbon and energy metabolism of oxidase positive saprophytic fluorescent Pseudomonas spp. Agronomie, v.17, n.9-10, p.427-443, 1997.

Revista Árvore, Viçosa-MG, v.37, n.1, p.41-47, 2013
LEMOS, M. T. O. Prospecção de rizobactérias promotoras de crescimento em quatro espécies arbóreas nativas do Brasil. 2009. $72 \mathrm{f}$. Dissertação (Mestrado em Microbiologia Agropecuária) - Universidade Estadual de São Paulo, Jaboticabal, 2009.

LUZ, W. C. Rizobactérias promotoras de crescimento de plantas e de bioproteção. Revisão Anual de Patologia de Plantas, v.4, p.1-49, 1996.

LUZ, W. C. Microbiolização de sementes para o controle de doenças de plantas. Revisão Anual de Patologia de Plantas, v.1, p.33-77, 1993.

MADIGAN, M. T. Extremophilic bacteria and microbial diversity. Annals of the Missouri Botanical Garden, v.87, n.1, p.3-12, 2000.

MAFIA, R. G. et al. Microbiolização e interação entre rizobactérias promotoras do crescimento e clones de eucalipto. Revista Árvore, v.33, n.5, p.789-797, 2009.

MAFIA, R. G. et al. Indução do enraizamento e crescimento do eucalipto por rizobacterias: efeito da adição de fonte alimentar e da composição do substrato de enraizamento. Revista Árvore, v.31, n.4, p.589-597, 2007.

MAFIA, R. G. et al. Crescimento de mudas e produtividade de minijardins clonais de eucalipto tratados com rizobactérias selecionadas. Revista Árvore, v.29, n.6, p.843-851, 2005.

MARQUES, E. Murcha bacteriana do eucalipto causada por Ralstonia solanacearum Raça 3 biovar 2T: etiologia, influência do solo e controle. 2012. 185f. Tese (Doutorado em Fitopatologia) Universidade de Brasília, Brasília, 2012.

MENDES, I. C.; REIS Jr., F. B. Microrganismos do solo e a sustentabilidade dos agroecossistemas. Disponível em: <http:// www.cpac.embrapa.br/noticias/artigosmidia/ publicados/188/>. Acesso em: 06 ago. de 2011.

MOREIRA, F. M. S.; SIQUEIRA, J. O.

Microbiologia e bioquímica do solo. Lavras: Universidade Federal de Lavras, 2006. 729p. 
PAZ, I. C. P. Bactérias endofíticas de eucalipto e potencial uso no controle de doenças e promoção de crescimento de mudas em viveiros florestais. 2009. 129f. Tese (Doutorado em Fitotecnia) - Universidade Federal do Rio Grande do Sul, Porto Alegre, 2009.

PROCÓPIO, R. E. Diversidade de bactérias endofiticas de Eucalyptus spp. e avaliação do seu potencial biotecnológico. 2004. 120f. Tese (Doutorado em Biotecnologia) - Universidade de São Paulo, Piracicaba, 2004.

REZENDE, A. M. F. A. Bactérias extremófilas facultativas: efeito na promoção de crescimento de tomate e na supressão de $R$. solanacearum. 2010. 156f. Tese (Doutorado em Fitopatologia) Universidade de Brasília, Brasília, 2010.

RODRIGUES, L. M. R. Avaliação da agressividade e caracterização genética de linhagens de Ralstonia solanacearum isoladas de diferentes plantas hospedeiras. 2010. 79f. Dissertação (Mestrado em Agronomia) - Universidade Estadual Paulista, Botucatu, 2010.

ROMEIRO, R. S. Controle biológico de doenças de plantas. Viçosa, MG: Universidade Federal de Viçosa, 2007. 172p.

SILVA, F. A. S.; AZEVEDO, C. A. V. Principal components analysis in the software assistatstatistical attendance. In: WORLD CONGRESS ON COMPUTERS IN AGRICULTURE., 7. 2009, Reno. Proceedings... Reno: American Society of Agricultural and Biological Engineers, 2009.
SIQUEIRA, J. O. Biologia do solo. Lavras: ESAL/FAEPE, 1993. 230p.

SOCIEDADE BRASILEIRA DE SILVICULTURASBS. Disponível em: <http://www.sbs.org.br/ FatoseNumerosdoBrasilFlorestal.pdf $>$. Acessado em: 06 jun.de 2010.

TEIXEIRA, D. A. et al. Rhizobacterial promotion of eucalypt rooting and growth. Brazilian Journal of Microbiology, v.38, n.1, p.118123, 2007.

TEIXEIRA, D. A. Promoção do enraizamento e indução de resistência sistêmica à ferrugem e à mancha-decyllindrocladium, mediadas por rizobactérias em clones de Eucalyptus spp. 2001. 67f. Tese (Doutorado em Fitopatologia) - Universidade Federal de Viçosa, Viçosa, MG, 2001.

ZAGO, V. C. P.; DE-POLLI, H.; RUMJANEK, N. G. Pseudonomas spp. Fluorescentes Bactérias promotoras de crescimento de plantas e biocontroladoras de fitopatógenos em sistemas de produção agrícola. Seropédica: Embrapa Agrobiologia, 2000. 32p. (Embrapa-CNPAB. Documentos, 127).

ZARPELON, T. G. Caracterização de rizobactérias e eficiência do Rizolyptus $^{\circledR}$ no enraizamento e crescimento do eucalipto. 2007. 82f. Tese (Mestrado em Fitopatologia) - Universidade Federal de Viçosa, Viçosa, MG, 2007. 
